\title{
The isolation of isoagathenediol: a new tricyclic diterpene from the lipids of Rhodospirillum rubrum
}

\author{
Jo-Anne Chuck $f$ and Kevin D. Barrow
}

Author for correspondence: Jo-Anne Chuck. Tel: +453327 5229. Fax: +4533274766.

e-mail: chuck@biobase.dk

School of Biochemistry and Molecular Genetics, University of New South Wales, Sydney 2052, Australia

\begin{abstract}
A tricyclic diterpene, isoagathenediol, has been isolated from the lipid fraction of the photosynthetic non-sulphur bacterium Rhodospirillum rubrum. The compound was present in trace amounts and its structure was determined by NMR spectroscopy and mass spectrometry. Isoagathenediol is a new natural product and may function as a membrane fluidity modulator. Five other bacterial species have also been screened for the presence of this compound, but the diterpene was detected only in extracts derived from $R$. rubrum. As tricyclic diterpene fossils are readily detected in oil and shale samples, the isolation of isoagathenediol has indicated the biological origin of these fossils.
\end{abstract}

Keywords: Rhodospirillum rubrum, isoprenoids, lipids, hopanoids, diterpenes

\section{INTRODUCTION}

Rhodospirillaceae are photosynthetic non-sulphur bacteria which are found in fresh water, marine and hypersaline environments such as lakes, marshes and paddy fields (Imhoff \& Trüper, 1989). Members of this family are thought to be unique amongst contemporary organisms as they contain the genetic material for all or most modes of energy metabolism (Youvan \& Bylina, 1989). For example, Rhodospirillum rubrum is able to grow as a photoheterotroph or photoautotroph under anaerobic conditions in the light, as well as being capable of microaerophilic or aerobic growth in the dark (Trüper \& Imhoff, 1989).

Terpenoid compounds play important roles in the photosynthetic processes of $R$. rubrum. The light harvesting bacteriochlorophyll $a$ from this organism has mainly geranylgeraniol, and to a minor extent phytol, esterified to the porphyrin (Jones, 1978). This is in comparison with most other species which possess phytol and farnesol (Brockman \& Knobloch, 1972). Carotenoids of the spirilloxanthin series (Schmidt, 1978) and membrane fluidity modulators (hopanoids) are also found as lipid constituents (Rohmer et al., 1984).

\footnotetext{
†Present address: Carlsberg Laboratory, Department of Physiology, Gamle Carlsberg vej, 10 DK-2500 Copenhagen Valby, Denmark.

Abbreviations: $\mathrm{Cl}$, chemical ionization; COSY, ${ }^{1} \mathrm{H}-{ }^{1} \mathrm{H}$ homonuclear correlated spectroscopy; DEPT, distortionless enhancement by polarization transfer; El, electron impact ionization; FID, flame ionization detection; HOHAHA, homonuclear Hartman Hahn transfer.
}

This investigation reports the isolation of a new class of diterpene, isoagathenediol, in the lipids of this organism. This is also the first report of the isolation of this compound as a natural product. The structure of isoagathenediol is such that it could function as a membrane fluidity modulator in a similar manner to the hopanoids. Its isolation as a prokaryotic lipid indicates the origin of some of the diterpene biomarkers which are detected in oil and shale sediments (Anders \& Robinson, 1971; Chicarelli et al., 1988).

\section{METHODS}

Organism. Rbodospirillum rubrum Van Neils strain S1 (UNSW 009500) was obtained from the School of Microbiology University of NSW, Kensington, Australia. The organism was cultured anaerobically in the medium of Ormerod et al. (1961) in four 201 carboys at $30^{\circ} \mathrm{C}$ under the illumination of tungsten lamps for $10 \mathrm{~d}$. The cells were harvested by centrifugation $\left(5000 \mathrm{~g}, 10 \mathrm{~min}\right.$ at $\left.5^{\circ} \mathrm{C}\right)$, washed and freeze-dried $(90 \mathrm{~g}$ dry $\mathrm{wt})$.

Isolation of isoagathenediol monoacetate. A lipid fraction was obtained by refluxing the cells in $\mathrm{CHCl}_{3} / \mathrm{CH}_{3} \mathrm{OH}(2: 1, \mathrm{v} / \mathrm{v})$ for $2 \times 1 \mathrm{~h}$ and the evaporated filtrates were acetylated using pyridine/acetic anhydride $(1: 1, \mathrm{v} / \mathrm{v})$ for $18 \mathrm{~h}$ at room temperature. The evaporated extract (18 g) was dissolved in $\mathrm{CHCl}_{3}$ and separated by flash chromatography (Still et al., 1978) using a column of Merck $60 \mathrm{H}$ silica gel $(14 \times 8 \mathrm{~cm}$ i.d.). The column was equilibrated with hexane and fractions $(200 \mathrm{ml})$ of the following solvents were passed sequentially through the column under the suction of a water pump and collected separately; hexane, hexane/ethyl acetate $(95: 5, \mathrm{v} / \mathrm{v})$, hexane/ethyl acetate $(9: 1, \mathrm{v} / \mathrm{v})$, hexane/ethyl acetate $(4: 1, \mathrm{v} / \mathrm{v})$, hexane/ethyl acetate $(3: 1, v / v)$, hexane/ethyl acetate $(7: 3, v / v)$, hexane/ethyl acetate 
$(1: 1, v / v)$, ethyl acetate and $\mathrm{CH}_{3} \mathrm{OH}$. Thin layer chromatography (TLC) was carried out using Polygram SIL-HR/UV254 plates (Macherey-Nagel) developed in paper-lined tanks using toluene/ethyl acetate $(95: 5, \mathrm{v} / \mathrm{v})$ and visualized by spraying with $50 \%(\mathrm{v} / \mathrm{v}) \mathrm{H}_{2} \mathrm{SO}_{4}$ and charring on a hot plate (diterpene acetate $R_{F} 0 \cdot 3$ ).

Fractions 5 and 6 were pooled and further purified using a rotary Chromatotron (Model 7924T, Professional Technology Pty Ltd) and a $2 \mathrm{~mm}$ silica gel (Merck, $60 \mathrm{PF}_{254}$ ) rotor using toluene as a solvent $(50 \mathrm{ml})$. Fractions $(4 \mathrm{ml})$ were collected and analysed by TLC. Fractions 9 and 10 were further purified by HPLC using a Whatman Partisil M9 10/50 normal phase column with a Waters Differential Refractometer R401 detector and a solvent system of toluene/ethyl acetate $(6: 4, \mathrm{v} / \mathrm{v})$ at a flow rate of $3 \mathrm{ml} \mathrm{m^{-1 }}$ (diterpene acetate, retention time $15.5 \mathrm{~min}$ ). A Gold Pak EXSIL 100, $5 \mu \mathrm{m}$ silica gel column (Activon) using a

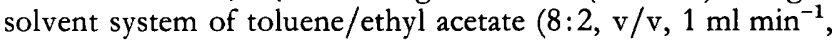
retention time $4.0 \mathrm{~min}$ ) was used as a final purification step. The compound $(16 \mathrm{mg})$ was recrystallized from hot acetonitrile and purity assessed by gas chromatography using a Hewlett Packard $5890 \mathrm{GC}$ with a $15 \mathrm{~m} \mathrm{SE}-30$ capillary column (Alltech), a $\mathrm{H}_{2}$ flow rate of $12 \mathrm{ml} \mathrm{min}^{-1}$, an oven temperature which increased from 200 to $280^{\circ} \mathrm{C}$ at $10^{\circ} \mathrm{C} \mathrm{min}^{-1}$ and flame ionization detection (FID) (retention time $7.2 \mathrm{~min}$ ).

Preparation of isoagathenediol. Isoagathenediol monoacetate (4 mg) was deacetylated by dissolving in $\mathrm{CH}_{3} \mathrm{OH}(0.5 \mathrm{ml})$ and adding $2 \mathrm{M} \mathrm{NaOH}(0.5 \mathrm{ml})$. The reaction was carried out at $30{ }^{\circ} \mathrm{C}$ for $2 \mathrm{~h}$ and then acidified with $1 \mathrm{M} \mathrm{HCl}$. After extraction with $\mathrm{CHCl}_{3}(4 \times 1.5 \mathrm{ml})$, the reaction products were analysed by normal phase TLC (isoagathenediol, $R_{F} 0 \cdot 1$ ). Final purification of the diol was by HPLC in the previously described system using the Gold Pak $5 \mu \mathrm{m}$ silica column (retention time of the diol $9 \mathrm{~min}$ ).

Physical analyses. Infra red spectra were recorded in $\mathrm{CHCl}_{3}$ on a Perkin-Elmer 580B infra red spectrometer. Melting points were carried out using a Buchi type $\mathrm{S}$ melting point apparatus. Optical rotations were determined in $\mathrm{CHCl}_{3}$ using a PerkinElmer 141 polarimeter.

Chemical ionization (CI) spectra using methane as the ionization gas were recorded using a Finnigan Model 3200 mass spectrometer. Isoagathenediol monoacetate CI positive ion spectrum (direct insertion): $m / z, 351(2 \%), 333(20 \%), 317(6 \%)$, $281(5 \%), 273(65 \%), 263(7 \%), 257(12 \%), 207(30 \%), 205$ $(15 \%), 171(13 \%), 163(15 \%), 149(65 \%), 61(100 \%)$. Electron impact ionization (EI) mass spectra were recorded using a VG AUTOSPEC-Q mass spectrometer operating at a filament emission energy of $70 \mathrm{eV}$ and a source temperature of $180^{\circ} \mathrm{C}$. Isoagathenediol monoacetate EI positive ion spectrum (direct insertion): $m / z, 290(12 \%), 275(7 \%), 205(10 \%), 191(43 \%)$, $137(6 \%), 123(15 \%), 95(17 \%), 69(37 \%)$.

${ }^{1} \mathrm{H}$ and ${ }^{13} \mathrm{C}$ NMR spectra were recorded on a Bruker AM 500 spectrometer operating at $500 \mathrm{MHz}$ and $125 \mathrm{MHz}$, respectively. Spectra were recorded on samples containing $\mathrm{CDCl}_{3}$ and chemical shifts were expressed in p.p.m. downfield from $\mathrm{Me}_{4} \mathrm{Si}$. In the case of the ${ }^{13} \mathrm{C}$ spectra, the reference was $\mathrm{CDCl}_{3}$, with the centre of the triplet resonating at $77 \cdot 0$ p.p.m. relative to $\mathrm{Me}_{4} \mathrm{Si}$. ${ }^{1} \mathrm{H}-{ }^{1} \mathrm{H}$ homonuclear shift correlated (COSY) spectra were recorded using $90^{\circ}$ and $45^{\circ}$ pulses of 12 and $6 \mu \mathrm{s}$, respectively, and a recycle time of $2 \mathrm{~s}$. Homonuclear Hartman Hahn transfer (HOHAHA) spin locked experiments were run using the MLEV-17 sequence (Bax \& Davis, 1985) with mixing times of 65-70 ms and $90^{\circ}$ and $180^{\circ}$ pulse widths of 35 and $70 \mu \mathrm{s}$, respectively, and a recycle delay of $2 \mathrm{~s}$. Distortionless enhancement by polarization transfer (DEPT) spectra were run with the standard Bruker program. Carbon-proton correlations (heteronuclear shift correlated 2D) were carried out using the sequence of Wilde \& Bolton (1984). The $90^{\circ}{ }^{1} \mathrm{H}$ pulse width was $11 \mu \mathrm{s}$ and the carbon $90^{\circ}$ and $180^{\circ}$ pulses were 5.5 and $11 \mu \mathrm{s}$, respectively. A heteronuclear $J$-resolved $2 \mathrm{D}$ NMR spectrum was obtained with $90^{\circ}$ and $180^{\circ}$ carbon pulses of 5.5 and $11 \mu \mathrm{s}$, respectively. A long range carbon-proton correlation experiment was carried out using the sequence of Reynolds et al. (1985), a $2 \mathrm{~s}$ recycle time and delays of $0.011 \mathrm{~s}$ and $0.22 \mathrm{~s}$.

\section{RESULTS}

Isoagathenediol monoacetate [melting point $159^{\circ} \mathrm{C}$ (corrected), literature $159-161^{\circ} \mathrm{C}$; Imamura \& Ruveda, 1980; Fig. 1] was isolated from the acetylated lipids of $R$. rubrum (16 $\mathrm{mg}$ per $90 \mathrm{~g}$ dry wt of cells). The compound could not be detected by TLC of the crude acetylated lipid extract of the organism. Partial purification of the extract
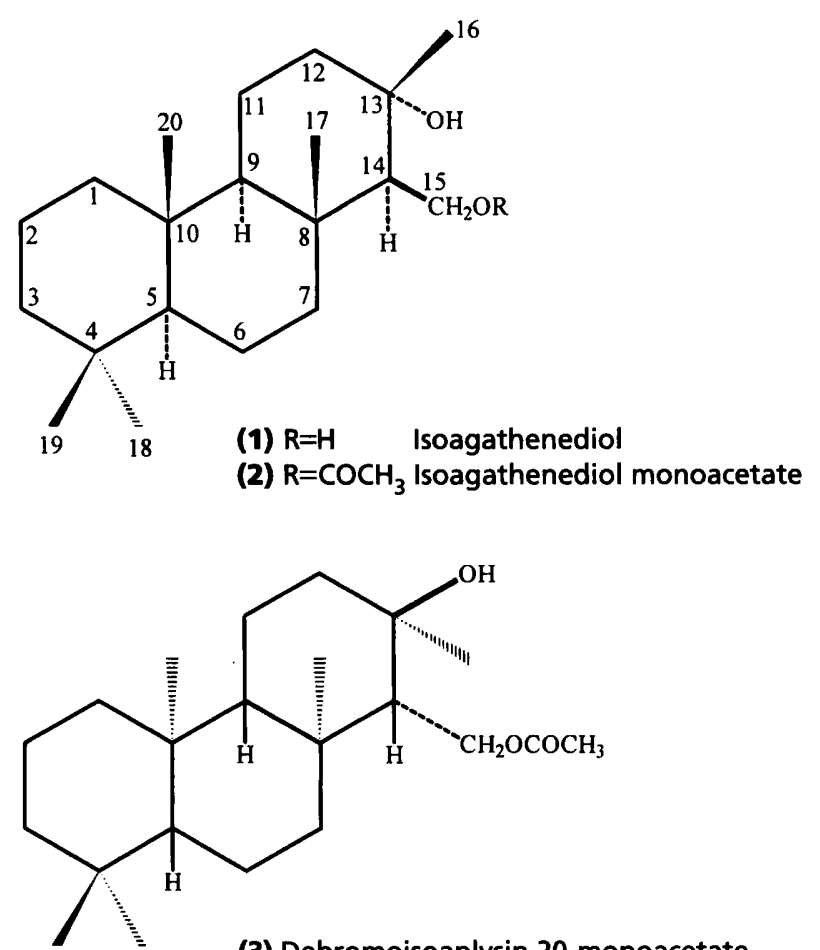

(3) Debromoisoaplysin 20-monoacetate

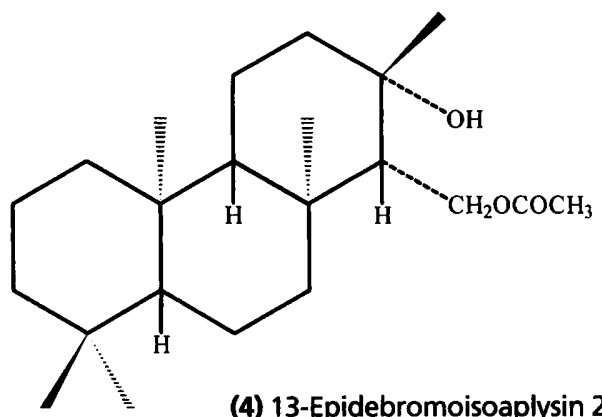

(4) 13-Epidebromoisoaplysin 20-monoacetate

Fig. 1. The structure of isoagathenediol and the monoacetate derivative isolated in this investigation. Debromoisoaplysin 20monoacetate and 13-epidebromoisoaplysin 20-monoacetate synthesized by Imamura \& Ruveda (1980) are also shown for comparison. 
Table 1. ${ }^{13} \mathrm{C}$ and ${ }^{1} \mathrm{H}$ NMR assignments for isoagathenediol monoacetate

The numbering of the carbon atoms is shown in Fig. 1.

\begin{tabular}{|c|c|c|c|c|c|}
\hline $\begin{array}{l}\text { Carbon } \\
\text { atom }\end{array}$ & $\delta^{13} \mathrm{C}$ & $\delta^{1} \mathbf{H}$ & $J(\mathbf{H z})$ & $\delta^{1} \mathbf{H}$ & $J(\mathbf{H z})$ \\
\hline 1 & $40 \cdot 0$ & 0.86 & & 1.69 & \\
\hline 2 & $18 \cdot 1$ & $1 \cdot 42$ & & 1.61 & \\
\hline 3 & $42 \cdot 0$ & $1 \cdot 18$ & & $1 \cdot 43$ & \\
\hline 4 & $33 \cdot 2$ & - & & - & \\
\hline 5 & $56 \cdot 4$ & $0 \cdot 88$ & & - & \\
\hline 6 & $18 \cdot 6$ & $1 \cdot 56$ & & $1 \cdot 38$ & \\
\hline 7 & $41 \cdot 4$ & $1 \cdot 76$ & & $1 \cdot 18$ & \\
\hline 8 & $37 \cdot 5$ & - & & - & \\
\hline 9 & $60 \cdot 3$ & $0 \cdot 97$ & & - & \\
\hline 10 & $38 \cdot 4$ & - & & - & \\
\hline 11 & $19 \cdot 1$ & $1 \cdot 27$ & & $1 \cdot 64$ & \\
\hline 12 & $43 \cdot 8$ & $1 \cdot 47$ & & $1 \cdot 88$ & \\
\hline 13 & $72 \cdot 4$ & - & & - & \\
\hline 14 & $60 \cdot 2$ & 1.55 & & - & \\
\hline 15 & 62.5 & $4 \cdot 37$ & $11.9 ; 7 \cdot 0$ & $4 \cdot 29$ & $11.9 ; 4.9$ \\
\hline 16 & $24 \cdot 4$ & $1 \cdot 20$ & & - & \\
\hline 17 & $17 \cdot 0$ & 0.89 & & - & \\
\hline 18 & $33 \cdot 4$ & 0.89 & & - & \\
\hline 19 & $21 \cdot 4$ & 0.84 & & - & \\
\hline 20 & $16 \cdot 3$ & 0.84 & & - & \\
\hline 21 & $171 \cdot 3$ & - & & - & \\
\hline 22 & $21 \cdot 3$ & $2 \cdot 08$ & & - & \\
\hline
\end{tabular}

using flash chromatography allowed the diterpene to be detected. The compound gave a red/purple colour on the plate after spraying with $\mathrm{H}_{2} \mathrm{SO}_{4}$ and charring and this was quite distinct from the purple colour that the hopanoids and squalene develop after similar treatment. The compound did not absorb light at $254 \mathrm{~nm}$.

Isoagathenediol monoacetate was detected in the crude acetylated lipid extract of the organism by capillary GC using FID. The same extract, when chromatographed before acetylation, had no peaks in the chromatogram corresponding to the compound (results not shown), thus the diterpene must exist in the lipids of the organism in the unacetylated form. The structure of the compound was determined by extensive use of NMR spectroscopy and high resolution mass spectrometry.

\section{NMR analyses}

The proton NMR spectrum of isoagathenediol monoacetate indicated that the compound contained six quaternary methyl groups. A resonance at 1.20 p.p.m. was consistent with a methyl group close to an electron withdrawing group. The resonance at 2.08 p.p.m. indicated the presence of a methyl group of an acetate moiety. The compound also contained two methylene protons resulting in resonances at lower field centred at 4.33 p.p.m. The other proton resonances in the spectrum occurred in the chemical shift range of 0.8-2.4 p.p.m. (Table 1).
The ${ }^{13} \mathrm{C}$ spectrum of isoagathenediol monoacetate depicted 22 carbon resonances and, analogous to the ${ }^{13} \mathrm{C}$ spectra of other acetylated terpenes (Nishizawa et al., 1986), contained resonances at 171.3 p.p.m. and 21.3 p.p.m. These were the carbonyl and methyl carbon resonances of the acetoxy group added to the compound during derivatization. Due to the similarities of the spectrum with that of other cyclic terpenes, it appeared that the compound had a typical terpenoid A/B ring system (Wehrli \& Wirthlin, 1976).

DEPT experiments indicated that the unacetylated compound had eight $\mathrm{CH}_{2}$, five methyl groups, four quaternary carbons and three $\mathrm{CH}$ groups. This was consistent with the results obtained from a $2 \mathrm{D} J$-resolved heteronuclear experiment which also indicated that the coupling constants were all in the usual range of $125-150 \mathrm{~Hz}$ and thus excluded the existence of strained or small rings in the molecule (Wehrli \& Wirthlin, 1976). Assignment of the proton spectrum of the acetate derivative was carried out using the results of ${ }^{13} \mathrm{C}-{ }^{1} \mathrm{H}$ correlation experiments and on the basis of the carbon assignments by Nishizawa et al. (1986) for unacetylated compounds (Table 1).

A COSY spectrum of the molecule indicated that the two lower field protons at 4.29 and 4.37 p.p.m. were coupled to each other and to a proton at 1.55 p.p.m. These protons were assigned to $\mathrm{C}-15$ and were coupled to $\mathrm{H}-14$. A long range coupling was also seen from the two protons at $\mathrm{C}$ 15 to the methyl protons of the acetoxy group. The results of a HOHAHA experiment showed three spin systems in the ring proton region of the spectrum. With the results of the HOHAHA experiment and the DEPT experiments, seven of the $\mathrm{CH}_{2}$ groups were assigned to the three spin systems and the eighth to the carbon bearing the acetoxy group. Two of the $\mathrm{CH}$ groups were also involved in the spin systems of the ring protons while the third $\mathrm{CH}$ group (C-14), which was surrounded by quaternary ring carbons, showed coupling to the $\mathrm{CH}_{2}(\mathrm{C}-15)$ bearing the acetoxy group. The long range ${ }^{13} \mathrm{C}-{ }^{1} \mathrm{H}$ correlation experiment clearly confirmed the structure of the molecule around carbons 13, 14 and 15 and allowed for the interconnection of the spin systems detected in the HOHAHA experiment.

\section{Mass spectrometry and other analyses}

High resolution mass spectrometry was carried out on both the acetylated and unacetylated diol giving rise to very similar mass spectra. No molecular ion was evident in the spectra of the molecules using EI fragmentation; however, a pseudomolecular ion of low intensity $\left(m / z 351,[\mathrm{M}+1]^{+}, 2 \%\right)$ was evident in the CI spectra of the acetate derivative.

By EI, both compounds had a similar mass spectrum as the monoacetate derivative lost the acetate moiety and then both compounds lost water, presumably at the position of the tertiary hydroxyl group. This gave the ion $\mathrm{m} / \mathrm{z} 290(12 \%$ high resolution mass measurement found $m / z 290 \cdot 2610$; calculated for $\mathrm{C}_{20} \mathrm{H}_{34} \mathrm{O}\left(\left[\mathrm{M}-\mathrm{CH}_{3} \mathrm{COOH}\right]^{+}\right)$ $m / z 290 \cdot 2610)$ and the skeleton fragmented to give the ion $m / z 191(43 \%)$ in high abundance. 
An infra red spectrum of the diterpene monoacetate showed absorbance bands at 3597 and $1735 \mathrm{~cm}^{-1}$ which indicated the presence of a tertiary hydroxyl group and an acetate group in the molecule. On deacetylation, the carbonyl band was missing and implied that the molecule contained two hydroxyl groups, of which only one was acetylated under the experimental conditions used.

\section{Determination of complete configuration of isoagathenediol}

The compound isolated in this investigation was identified as the enantiomer of a compound synthesized by Imamura \& Ruveda (1980). Debromoisoaplysin 20-monoacetate (Fig. 1) had an identical melting point and ${ }^{1} \mathrm{H}$ NMR spectrum to the compound isolated in this investigation. The optical rotation of isoagathenediol monoacetate $\left([\alpha]_{D}=-3.7 ; c=0.004\right)$ though the same in magnitude, was laevorotatary rather than dexrorotatary. From the NMR spectrum of the synthetic compound 13-epidebromoisoaplysin 20-monoacetate (Fig. 1), the stereochemistry of the hydroxyl group compared with the carbon at C-15 was determined. The $1 \mathrm{D}{ }^{1} \mathrm{H}$ NMR spectrum of this compound had the resonance of the methyl group at C-13 at 1.02 p.p.m. compared with the diterpene isolated in this investigation where the methyl group was at 1.20 p.p.m.

Nishizawa et al. (1986) also synthesized the diol (spongia$13 \alpha, 15$-diol) as a racemic mixture. They synthesized various isomers of the compound with isomeric methyl groups and hydroxyl groups in ring $\mathrm{C}$. The comparison of the ${ }^{13} \mathrm{C}$ spectrum of the diterpene isolated in this investigation with the spectra of the analogue allowed for the determination of the stereochemistry of isoagathenediol $(13 \alpha \mathrm{OH}, 14 \alpha \mathrm{H})$.

\section{DISCUSSION}

Isoagathenediol is a new microbial lipid and is not a previously known natural product. It has, however, been chemically synthesized (Nishizawa et al., 1986; Vlad et al., 1986) and named according to Vlad et al. (1986) based on the nomenclature of isoagatholactone. Previous to this study, the only known microbial diterpenes were the carotenoid intermediate, geranylgeraniol pyrophosphate (Langworthy, 1982), a chemically uncharacterized gibberellin from Azotobacter vinelandii (Lee et al., 1970) and verrucosan-2 $\beta$-ol from Chloroflexus aurantiacus (Hefter et al., 1993).

Five other prokaryotes, including those known to contain hopanoids, were screened for the presence of the diterpene by GC of crude acetylated lipid extracts (results not shown). In acetylated extracts derived from Rbodopseudomonas palustris, Alicyclobacillus acidocaldarius, Zymomonas mobilis, Rbodobacter capsulatus and Rhodopseudomonas viridis the diterpene could not be detected ( $<10 \mu \mathrm{g}$ per $15 \mathrm{mg}$ of lipid extract). This may be due to the composition of bacteriochlorophyll $a$ of $R$. rubrum having geranylgeraniol as a constituent (Jones, 1978). It is likely that this molecule or geranylgeraniol pyro- phosphate would be the substrate for the cyclization reaction biosynthesizing the diterpene.

The cyclase giving rise to this diterpene appears to be distinct from those required for hopanoid and tetrahymanol biosynthesis. The substrate folding for the active site of the enzyme would require an all pre-chair folding in preparation for an 'all Markovnikov' reaction (Ourisson \& Rohmer, 1982). Renoux \& Rohmer (1986) have demonstrated the cyclization of hexaprenol methyl ether to an extended tricyclic product in a cell-free system of Tetrabymena pyriformis. It was assumed that the squalene cyclase was responsible for the synthesis and this was supported by the fact that the cyclization of both the enantiomers of squalene epoxide was demonstrated by the preparation indicating a lack of substrate specificity. The stereochemistry of these products at the side chain of the molecule was different to the diterpene isolated in this investigation. It was assumed that the substrate had adopted a chair, chair, boat conformation in the active site of the cyclase resulting in an axial side chain (Renoux \& Rohmer, 1986). This suggests that isoagathenediol is cyclized by a different enzyme to the squalene cyclases.

As terpenoid compounds are very recalcitrant they are often detected in sediment samples such as oil or shale and are used to determine the source and age of organic matter making up the sediment. Geochemical analysis of Irati shale has shown that $\mathrm{C}_{20}$ diterpene isomers $13 \beta \mathrm{H}, 14 \alpha \mathrm{H}$ and $13 \alpha \mathrm{H}, 14 \alpha \mathrm{H}$ are abundant, with approximately equal quantities of the isomers (Chicarelli et al., 1988). This would be consistent with the stereochemistry of isoagathenediol $(13 \alpha \mathrm{OH}, 14 \alpha \mathrm{H})$ which, via the maturation process of the sediment, would rapidly dehydrate at the position of the tertiary hydroxyl group. Thus the stereochemistry of the methyl group at $\mathrm{C}-13$ would be lost and the double bond between $\mathrm{C}-12$ and $\mathrm{C}-13$ could be saturated above or below the plane of the ring to give the stereochemistry of the two predominate isomers. The generation of isomers of sterols in sediments via the hydrogenation of ring double bonds is well documented (Mackenzie et al., 1982). This investigation again reinforces the importance of the characterization of lipid components of organic sediments to gain knowledge about existing lipids.

Isoagathenediol is a planar compound with the hydroxyl groups at one end of the molecule. According to Ourisson \& Rohmer (1982), for molecules to optimize the mechanical properties of a membrane, the compound must have a hydrophilic head and a lipophilic body. To enable close packing with the acyl chains of lipids, the molecule must be approximately $6 \AA$ thick and $6 \AA$ wide. Isoagathenediol fulfills this criterion as it is approximately $6 \AA$ high, $6 \AA$ wide and $11 \AA$ long (dimensions determined using a scaled model). Like the hopanoids, this compound could be incorporated into the membranes of $R$. rubrum in a sterol-like manner and function as a membranereinforcing molecule. This has yet to be confirmed by biophysical analyses.

Prior to this study, structurally related tricyclic diterpenes had not been isolated from a biological source even 
though they were readily detected in sediment samples and so it was assumed that the molecules were derived from unknown or ancient organisms (Ourisson \& Rohmer, 1982; Brassell et al., 1983). If the evolutionary model of Rohmer et al. (1979) is accepted, with membrane stability maintained by carotenoids and tetraterpenes prior to the evolution of a cyclase, the enzyme would be likely to use a carotenoid or tetraterpene precursor as a substrate. Isoagathenediol may thus be more primitive than hopanoids as its biosynthesis does not require the synthesis of squalene but an intermediate from carotenoid biosynthesis, geranylgeraniol. It is likely that the diterpene, however, acts as a less effective membrane stabilizer due to the reduced length of its hydrophobic region and thus evolution has selected for the squalene cyclase in most bacteria.

\section{ACKNOWLEDGEMENTS}

We would like to thank David Bourne for carrying out the mass spectral analyses and Poul Strøbech for technical assistance.

\section{REFERENCES}

Anders, D. E. \& Robinson, W. E. (1971). Cycloalkane constituents of bitumen from Green River Shale. Geochim Cosmocbim Acta 35, 661-678.

Bax, A. \& Davis, D. G. (1985). MLEV-17 based two dimensional homonuclear magnetization transfer spectroscopy. J Magn Reson 65, 335-360.

Brassell, S. C., Eglinton, G. \& Maxwell, J. R. (1983). The geochemistry of terpenoids and sterols. Biochem Soc Trans 11, 575-586.

Brockmann, H., Jr. \& Knobloch, G. (1972). Ein neues bacteriochlorophyll aus Rbodospirillum rubrum. Arch Mikrobiol 85, 123-126.

Chicarelli, M. I., Aquino Neto, F. R. \& Albrecht, P. (1988). Occurrence of four stereoisomers of tricyclic terpene series in immature Brazilian Shale. Geochim Cosmochim Acta 52, 1955-1959.

Hefter, A., Richmow, H. H., Fischer, U., Trendel, J. M. \& Michaelis, W. (1993). ( - )-Verrucosan-2 $\beta$-ol from the phototrophic bacterium Chloroflexus aurantiacus: first report of a verrucosane-type diterpene from a prokaryote. J Gen Microbiol 139, 2757-2761.

Imamura, P. M. \& Ruveda, E. A. (1980). The C-13 configuration of the bromine-containing diterpene isoaplysin-20. Synthesis of debromoisoaplysin-20 and its C-13 epimer. J Org Chem 45, 510-515.

Imhoff, J. F. \& Truper, H. G. (1989). Purple nonsulfur bacteria. In Bergey's Manual of Systematic Bacteriology, vol. 3, pp. 1658-1662. Edited by J. T. Staley, M. P. Bryant, N. Pfennig \& J. G. Holt. Baltimore: Williams \& Wilkins.

Jones, O. T. G. (1978). Biosynthesis of porphyrins, hemes and chlorophylls. In The Photosynthetic Bacteria, pp. 751-777. Edited by R. K. Clayton \& W. R. Sistrom. New York: Plenum Press.

Langworthy, T. A. (1982). Lipids in bacteria living in extreme environments. Curr Top Membr Transp 17, 45-77.

Lee, M., Breckenridge, C. \& Knowles, R. (1970). Effects of some culturing conditions on the production of indole-3-acetic acid and a gibberellin-like substance by Azotobacter vinelandii. Can J Microbiol 16, 1325-1330.

Mackenzie, A. S., Brassell, S. C., Eglinton, G. \& Maxwell, J. R. (1982). Chemical fossils: the geological fate of steroids. Science 217, 491-504.

Nishizawa, M., Takenaka, H. \& Hayashi, Y. (1986). Chemical simulation of polycyclic diterpenoid biosynthesis using mercury (II) triflate/ $N, N$-dimethylaniline complex: mechanistic aspects of biomimetic olefin cyclization. J Org Chem 51, 806-813.

Ormerod, J. G., Ormerod, K. S. \& Gest, H. (1961). Light dependent utilization of organic compounds and photoproduction of molecular hydrogen by photosynthetic bacteria; relationship with nitrogen metabolism. Arch Biochem Biopbys 94, 449-463.

Ourisson, G. \& Rohmer, M. (1982). Prokaryotic polyterpenoids: phylogenetic precursors of sterols. Curr Top Membr Transp 17, 153-182.

Renoux, J. M. \& Rohmer, M. (1986). Enzymatic cyclization of all trans pentaprenyl and hexaprenyl methyl ethers by a cell free system from the protozoon Tetrabymena pyriformis. Eur $J$ Biochem 155, 125-132.

Reynolds, W. F., Hughes, D. W. \& Perpick-Dumont, M. (1985). A pulse sequence for establishing carbon-carbon connectivities via indirect ${ }^{13} \mathrm{C}-{ }^{1} \mathrm{H}$ polarization transfer modulated by vicinal ${ }^{1} \mathrm{H}-{ }^{1} \mathrm{H}$ coupling. J Magn Reson 63, 413-417.

Rohmer, M., Bouvier, P. \& Ourisson, G. (1979). Molecular evolution of biomembranes: structural equivalents and phylogenetic precursors to sterols. Proc Natl Acad Sci US A 76, 847-851.

Rohmer, M., Bouvier, P. \& Ourisson, G. (1984). Distribution of hopanoid triterpenes in prokaryotes. $J$ Gen Microbiol 130, 11371150.

Schmidt, K. (1978). The biosynthesis of carotenoids. In The Photosynthetic Bacteria, pp. 729-750. Edited by R. K. Clayton \& W. R. Sistrom, New York : Plenum Press.

Still, W. C., Kahn, M. \& Mitra, A. (1978). A rapid chromatography technique for preparative separations with moderate resolution. $J$ Org Chem 43, 2923-2925.

Truper, H. G. \& Imhoff, J. F. (1989). Genus Rhodospirillum Molisch 1907, 24 ${ }^{\mathrm{AL}}$. In Bergey's Manual of Systematic Bacteriology, vol. 3, pp. 1662-1667. Edited by J. T. Staley, M. P. Bryant, N. Pfennig \& J. G. Holt. Baltimore: Williams \& Wilkins.

Vlad, P. F., Ungur, N. D. \& Perutskii, V. B. (1986). Cyclization and rearrangements of diterpenes $V$. Structure-selective stereospecific cyclization of all trans geranylgeraniol and its acetate derivative by fluorosulfonic acid. Khim Prir Soedin 4, 514-515.

Wehrli, F. W. \& Wirthlin, T. (1976). Interpretation of Carbon-13 NMR Spectra. New York: Heyden Press.

Wilde, J. A. \& Bolton, P. H. (1984). Suppression of homonuclear couplings in heteronuclear two dimensional spectroscopy. J Magn Reson 59, 349-354.

Youvan, D. C. \& Bylina, E. J. (1989). Photosynthesis in Rhodospirillaceae. In Genetics of Bacterial Diversity, pp. 87-106. Edited by D. A. Hopwood \& K. E. Chater. London: Academic Press.

Received 8 March 1995; revised 26 May 1995; accepted 6 June 1995. 